\title{
The Efficient Use of Literature in Second Language Education: Free Reading and Listening to Stories
}

\author{
Beniko Mason \\ Shitennoji University Junior College \\ (2013) In "Children's Literature in Second Language Education" \\ (Eds.) Janice Bland \& Christiane Lütge. Pages, 25-32. \\ ISBN: 9781441183521

\begin{abstract}
This paper describes studies that investigated the effects and efficiency of comprehension-based methodology in second language acquisition in Japan. The results of these studies consistently show that the combination of free reading and listening to stories is not only an effective means of foreign language acquisition, but is also highly efficient.
\end{abstract}

The critics of the Comprehension Hypothesis (as presented e.g. in Krashen, 1985) have long held the belief that comprehension-based methods are inefficient. Even though they have conceded that they are more effective than the traditionally used methods and that comprehensible input is necessary for language acquisition, they still claim that the combination of both traditional and comprehension approaches must be used in classrooms.

The following are studies that investigated exactly this point, whether comprehension-based methods are more efficient than the traditional methods and also more efficient than the combination of the two methodologies.

\section{Mason, B., and Krashen, S. (1997). Extensive Reading in English as a Foreign Language}

The first experiment in this study confirmed that pleasure reading could change reluctant "EFL" students to willing-to-read students at the university level in Japan. These students had failed in English study before, and were called Sai-Rishu (retaker) students. They did self-selected reading for one semester and learned to enjoy reading in English. They began the semester far behind the traditionally taught control group on a cloze test, but nearly caught up to them by the end of the semester showing that the method is not only effective but also efficient, let alone motivating. The effect size of the difference between the groups on the pretests was .72, but on the posttest it was only .25 .

In the second experiment, groups that did extensive reading outperformed traditionally taught groups at both university and junior college levels on the same cloze test $(\mathrm{N}=128)$. The effect sizes between the groups increased from .18 (pretest) to .62 (posttest) for the university group and from .11 to .84 for the junior college group; at the beginning the difference between the groups was small but at the end the difference between the experimental and control groups was substantial. The data also showed that students' writing improved because of self-selected reading.

The third experiment in this series compared the effects of self-selected reading and cloze 
exercises, a form-focused approach, as well as the effect of writing book summaries in Japanese vs. writing in English.

All groups gained on a cloze test after one academic year, with the English summary group doing significantly better than the cloze exercise group. Both reading groups did better than the cloze group on a test of reading comprehension. On a writing test (read a story and write a summary, rated by two raters), the Japanese writing group actually did best, a surprising result (see table 1).

Table 1. Extensive reading vs. intensive reading on cloze test

\begin{tabular}{|l|l|l|l|l|}
\hline Class & $\mathrm{n}$ & Pre test mean (SD) & Posttest mean (SD) & Gain \\
\hline ER: response in Japanese & 40 & $29.45(8.31)$ & $45.52(8.28)$ & 16.08 \\
\hline ER: response in English & 36 & $28.03(9.02)$ & $46.89(6.58)$ & 18.86 \\
\hline Cloze exercise class & 38 & $30.13(8.07)$ & $44.29(9.16)$ & 14.16 \\
\hline
\end{tabular}

\section{Mason, B. (2004). The Effect of Adding Supplementary Writing to an Extensive Reading Program}

This study investigated whether adding supplementary writing to an extensive reading program would increase its effectiveness for the development of grammatical accuracy when the treatment lasted for three semesters. As in a previous study (see above), all three groups did extensive reading, averaging 2300 pages in three semesters. One group wrote summaries of what they read in their first language, Japanese, another wrote summaries in English, and a third group wrote summaries in English that were corrected. All groups improved in written accuracy (number of error-free clauses per 100 words), and there were no significant differences among the groups.

Table 2 presents the effect sizes between the groups. Note that the group that wrote in Japanese was superior to all other groups in five out of six comparisons. (A plus sign indicates that the first group of each pair was superior.) The conclusion was that adding supplementary summary writing did not lead to greater accuracy and that it was therefore inefficient.

Table 2. Effect Sizes for Mason (2004)

\begin{tabular}{|l|l|l|l|}
\hline & Comparison Pairs & & \\
\hline Test & JSG:ESG & ESG: Correction & JSG: Correction \\
\hline Cloze & +0.12 & -0.02 & +0.15 \\
\hline Reading/TOEIC & +0.10 & -0.17 & -0.08 \\
\hline Error Free Clauses & +0.39 & 0.00 & +0.39 \\
\hline
\end{tabular}

$\mathrm{JSG}=$ Japanese summary group, ESG = English summary group, Correction $=$ English Summary plus Correction

The results of this study were consistent with those of many others showing that increasing output did not increase second language proficiency (Krashen, 2003), as well as Truscott's conclusion that error correction is of limited value (Truscott, 1996). Of course, one can 
always claim that more or different kinds of output are necessary, and that more and different kinds of correction will work, but the burden of proof is clearly on those who make these claims.

\section{Mason, B. (2005). Vocabulary Acquisition through Storytelling: Story-Listening vs. List Learning}

It has been demonstrated that vocabulary acquisition is possible from listening to stories (Elley, 1989), but it has also been argued that this source of vocabulary is insufficient and inefficient, that students need direct instruction as well (Nation, 1990). In this study, I attempted to confirm that listening to stories lead to the acquisition of vocabulary, and also attempted to determine how efficient this acquisition was, that is, how it compared to direct instruction.

Participants were first year college English majors in Japan. All students participated in both treatments. In the story-listening treatment, participants first took a pretest on 30 words (write a definition in Japanese). They then listened to a story, "The North Wind and the Sun," that contained the 30 words. The words on the sheet were written on the blackboard in front of the class. While the teacher told the story she pointed to the words on the board so that students could tell which word was used to tell the story. The story took about 20 minutes. After listening to the story, the participants retook the vocabulary test. A week later, the participants took an unexpected follow-up test on the same words presented in a different order.

The second treatment was given a week later, with a different list of 30 words. They were given the Japanese definitions of the words and were told to try to learn the words in the next 20 minutes, using any techniques they wanted to use. Students were allowed to work together. Subjects then took a posttest and a follow-up post-test one week later.

Table 3. Descriptive statistics of the story and list methods

\begin{tabular}{|l|l|l|l|l|l|}
\hline Variables & $\mathrm{N}$ & Mean & S.D. & Gain & Lost \\
\hline LIST PRE & 35 & 3.9 & 2.6 & & \\
\hline LIST POST & 35 & 28.5 & 2.6 & 24.6 & \\
\hline LIST DELAYED & 34 & 12.8 & 4.4 & 8.9 & 15.7 \\
\hline STORY PRE & 38 & 8.3 & 2.8 & & \\
\hline STORY POST & 38 & 17.2 & 4.7 & 8.9 & \\
\hline STORY DELAYED & 27 & 15.0 & 3.2 & 6.7 & 2.2 \\
\hline
\end{tabular}

As shown in table 3, the List method used in the second treatment was very successful on a test given immediately after studying the words, but there was a large drop in retention (63\% forgotten) on the delayed test. Far fewer words were forgotten after the story-telling treatment (25\%). Analysis of Covariance revealed that the adjusted means for the follow-up post-test were not significantly different (list-learning $=14.6$, story-telling $=13.2 F=1.5$, $p=.23$ ). 


\section{Mason, B., and Krashen, S. (2004). Is Form-Focused Vocabulary Instruction Worth While?}

In this study, we compared vocabulary growth in English as a foreign language through hearing a story with a combination of a story and supplementary activities designed to focus students specifically on learning the new words in the story. One group of college students heard a story with unfamiliar words (as in the design in the previous study), which took 15 minutes, and another (the "Story-Plus" group) heard a story and did supplementary form-focused activities, which took a total of 85 minutes.

The Story-Plus group was significantly better on all measures, including on a surprise follow-up test given five weeks later, learning about twice as many words as the Story-Only group. But the story-only group was as or more efficient: If we count time for testing, the Story-Only group acquired .15 words per minute ( 15 minutes for listening to a story and 5 minutes each taking the pre and post tests) and the Story-Plus group acquired .13 words per minute, nearly identical results. Not counting testing time, the story-only group looks even better, acquiring .25 words per minute.

The finding that story-listening is as effective as or more effective than traditional methods is encouraging. Stories are far more pleasant and engaging than traditional instruction, and students can gain other aspects of language from stories, as well as knowledge.

\section{Mason, B., Vanata, M., Jander, K., Borsch, R., and Krashen, S. (2009). The Effects and Efficiency of Hearing Stories on Vocabulary Acquisition by Students of German as a Second Foreign Language in Japan}

The studies in this paper were replications of the studies done in Mason (2005) and Mason $\&$ Krashen (2004) using German as a second foreign language by Japanese students. The subjects in these experiments had not studied German in their secondary schools and they did not read or hear German outside of school except for homework on grammar. Although the language used was their second foreign language, which was not as familiar to them as English was, the results were similar to the results in the previous studies.

The first experiment of the three included in this paper confirmed that hearing a story resulted in a higher acquisition/learning rate than the list method for beginning students of German as a foreign language. The second and third experiments confirmed that supplementary focus on form activities were not worthwhile for vocabulary acquisition/learning.

The next study demonstrated that the strong version of the comprehension theory, the combination of reading and listening, results in more efficient language acquisition than the combination of weak versions of both traditional, supplemented with a modest amount of comprehensible input.

\section{Mason, B. (2007). The Efficiency of Self-Selected Reading and Hearing Stories on Adult Second Language Acquisition}

One group consisting of Health Science majors listened to a fairy/folk tale for 30 to 40 
minutes in English every week in class told by the teacher and read graded readers at home (total of 18 hours of class time in one semester). The other group, English majors, took six other English classes using an audio lingual, form-based approach (total of 126 hours of class time in one semester) besides the same kind of reading class that the health science students took.

Both groups improved after one semester, but Health Science students' gains per hour of class-time were far greater; they were, in other words, more efficient. Table 4 presents improvements in accuracy as the ratio of error-free phrases to total phrases written. Again, the English majors made larger gains, but were less efficient.

Table 4. Percentage of error-free phrases

\begin{tabular}{|l|l|l|l|l|}
\hline & Pre-test & Post-test & gain & efficiency \\
\hline English & $47 \%(9.8 / 20.9)$ & $55 \%(28.2 / 51.6)$ & $8 \%$ & $.06(8 / 126)$ \\
\hline Health Science & $35 \%(6.2 / 17.6)$ & $40 \%(13 / 32.9)$ & $5 \%$ & $.28(5 / 18)$ \\
\hline
\end{tabular}

Another criticism for comprehension-based methods is that such easy and pleasant ways of acquiring language will not prepare students for academic proficiency, and that students need to be prepared for the TOEFL test. The goal of the next study was to investigate whether self-selected reading alone will improve TOEFL scores.

\section{Mason, B. (2006). Free Voluntary Reading and Autonomy in Second Language Acquisition: Improving TOEFL Scores from Reading Alone}

Previous research strongly suggests that reading is good preparation for the TOEFL. One case study (Constantino, 1995) and two multivariate correlational studies (Gradman and Hanania, 1991; Constantino, SY Lee, KS Cho, and Krashen, 1997) have shown that the amount of recreational reading students do is a strong predictor of TOEFL performance.

Showing that just engaging in independent reading improves scores on the TOEFL examination would have strong implications for both theory and practice. On the level of theory, it would confirm that language acquisition is possible from comprehensible input (in this case reading) alone. On the level of practice, it would tell us whether independent study is a viable and practical means of preparing for the TOEFL examination, especially if we can compare students' progress with those who prepare for the TOEFL examination in more traditional ways.

The subjects $(\mathrm{N}=6)$ in this study were well-educated, experienced language students, were highly motivated, and volunteered to engage in a reading program during the vacation time or when they were not attending English classes. Each chose somewhat different reading material, according to their own interests, with favorite authors including Sidney Sheldon, Paulo Coelho, Judy Blume, and Bertice Berry. In addition, several continued to read graded readers, familiar to them because of classes they had taken previously.

Subjects read for between one to four months, and took alternate forms of the TOEFL test before and after doing the reading. The average gain was 3.5 points per week on the overall 
test, and improvement was seen on all three components, listening (2.2 points), grammar (3.6 points), and reading (4.6 points). This gain is about the same as one sees with a full time TOEFL preparation class given in the United States and is consistent with the previous studies showing that reading is an excellent predictor of TOEFL performance.

\section{Mason, B. (2010). Impressive Gains on the TOEIC after One Year of Comprehensible Input, with No Output or Grammar Study.}

In this paper, I reported on a case that provides additional evidence for the "reading hypothesis" and also provides a clear direction for those who need to improve quickly. Mr. Tanaka was a 42 year-old man who worked in the radiology department in a local hospital in Osaka, Japan. After his graduation from vocational college, he had not studied English for 20 years.

Mr. Tanaka took the TOEIC examination in January 2009, after reading graded readers for six months (2590 pages), scoring 475 (255 in listening, and 220 in reading). He took it again one year later in January 2010, scoring 655 (330 in listening, and 325 in Reading). He thus gained 180 points in one year.

Between January 2009 and January 2010, Mr. Tanaka read 6456 pages, which took 217 hours. He also enrolled in a story listening class ( 30 hours): Thus his total input time was 247 hours. He improved .73 points on the TOEIC for each hour spent reading or listening (180 points improvement/247 hours). He informed me also that he had spent 70 hours of vocabulary study on his own. If we include the 70 additional hours of vocabulary study, his total investment in English was 317 hours and his rate of improvement was .57 points per hour.

Comparison with junior college English majors in Osaka (0.27), Japan who spent 500 hours of classroom instruction, and with international students in a TOEFL preparation course in an Intensive English Program in the US (0.13), showed that Mr. Tanaka's progress was much faster with almost no cost.

Table 5: Points gained per hour

\begin{tabular}{|l|l|l|l|}
\hline & Mr. Tanaka & English majors & TOEFL prep \\
\hline TOEIC & 0.73 & 0.27 & \\
\hline TOEFL & 0.25 & & 0.13 \\
\hline
\end{tabular}

English majors: from Pendergast (2010)

TOEFL prep: from Swinton (1983), discussed in Mason (2006)

\section{Summary and Conclusion}

This paper described studies that investigated the effects and efficiency of comprehension-based methodology in second language acquisition in Japan using Japanese university students and one older acquirer. What can be concluded from this series of studies is that comprehensible input-based methods, i.e. free reading (self-selected reading / extensive reading) and story-listening or the combination of both are not only an effective means of foreign language acquisition, but is also highly efficient despite the concerns 
expressed by some others.

\section{References}

Constantino, R. (1995), 'The effect of pleasure reading: Passing the TOEFL test doesn't have to hurt'. Mosaic, 3, (1), 15-17.

Constantino, R., Lee, S Y., Cho, K. S., and Krashen, S. (1997), 'Free voluntary reading as a predictor of TOEFL scores'. Applied Language Learning, 8, 111-118.

Elley, W. (1989), 'Vocabulary acquisition from listening to stories'. Reading Research Quarterly, 24, (2), 174-187.

Gradman, H., and Hanania, E. (1991), 'Language learning background factors and ESL Proficiency'. Modern Language Journal, 75, 39-51.

Krashen, S. (1985), The Input Hypothesis: Issues and Implications. Torrance, CA: Laredo Publishing Company Inc.

Krashen, S. (2003), Explorations in Language Acquisition and Use. Portsmouth, NH: Heinemann Publishing.

Krashen, S. (2004), The Power of Reading: Insights from the Research. Portsmouth, NH: Heinemann.

Mason, B. (2004), 'The effect of adding supplementary writing to an extensive reading program'. The International Journal of Foreign Language Teaching, 1, (1), 2-16.

Mason, B. (2005), 'Vocabulary acquisition through storytelling'. TexTESOL III Newsletter, February, 3-5.

Mason, B. (2006), 'Free voluntary reading and autonomy in second language acquisition: Improving TOEFL scores from reading alone'. The International Journal of Foreign Language Teaching, 2, (1), 2-5.

Mason, B. (2007), 'The efficiency of self-selected reading and hearing stories on adult second language acquisition. In Selected Papers from the Sixteenth International Symposium on English Teaching. Taipei: English Teachers' Association / ROC. Taipei, Taiwan. November 9-11, 2007, 630-633.

Mason, B. (2010), 'Impressive Gains on the TOEIC after one year of comprehensible input, with no output or grammar study'. Paper presented at the $19^{\text {th }}$ International Conference at English Teachers Association ROC, November, 12-14, 1997.

Mason, B., and Krashen, S. (1997), 'Extensive reading in English as a foreign language'. System, 25, (1), 91-102.

Mason, B., and Krashen, S. (2004), 'Is form-focused vocabulary instruction worth while?' RELC Journal, 35, (2), 179-185.

Mason, B.,Vanata, M., Jander, K., Borsch, R., and Krashen, S. (2009), 'The effects and efficiency of hearing stories on vocabulary acquisition by students of German as a second foreign language in Japan'. The Indonesian Journal of English Language Teaching, 5, (1), 1-14.

Nation, P. S. (1990), Teaching and Learning Vocabulary. New York: Heinle and Heinle.

Pendergast, T. (2010), 'English language proficiency gains in an integrated, self-access program class of 2005 Part 2: The ETS test battery'. Shitennoji University Junior College Journal, 49, 355-369

Swinton, S. S. (1983), TOEFL Research Reports, Report 14. Princeton, N.J.: Educational Testing Service.

Truscott, J. (1996), 'The case against grammar correction in L2 writing classes'. Language Learning, 46, 327-369. 